\title{
A EDUCAÇÃO AMBIENTAL NA EDUCAÇÃO A DISTÂNCIA: CONTRIBUIÇÕES À PRÁTICA PEDAGÓGICA DO CURSO DE FORMAÇÃO DE PROFESSORES EM GEOGRAFIA DA UNIVERSIDADE FEDERAL DE SERGIPE
}

Jailton Santos Silva ${ }^{1}$

Márcia Eliane Silva Carvalho²

Resumo: Este trabalho apresenta uma reflexão sobre a inserção da Educação Ambiental no curso de formação de professores de geografia da Universidade Federal de Sergipe na modalidade EAD e contribui como fundamentação teórico-prática para a Educação Ambiental. Para alcance dos objetivos, utilizaram-se levantamentos bibliográficos, pesquisas no sistema de gestão acadêmica da universidade e os relatos do minicurso "A Educação Ambiental e o ensino de geografia: reflexão e ação no cotidiano escolar". A partir das análises realizadas conclui-se que 0 referido curso tem incorporado a Educação Ambiental em seu currículo de ensino, refletindo um comprometimento social e uma preocupação com a qualidade da formação dos seus alunos.

Palavras-chave: Educação Ambiental; Educação a Distância; Formação de Professores; Geografia.

\footnotetext{
1 Universidade Federal de Sergipe. E-mail: jailton-santos25@hotmail.com
}

2 Universidade Federal de Sergipe. E-mail: marciacarvalho@ufs.br

Revbea, São Paulo, V. 12, No 2: 199-208, 2017.

revista brasileira educação ambiental 


\section{Introdução}

Com o passar do tempo a globalização marcada eminentemente pela aceleração e eficiência das informações regidas pela racionalidade das grandes corporações transnacionais têm modificado diversos setores da sociedade contemporânea, impondo a estes novas dinâmicas. O espaço geográfico tem agregado em si novos valores e costumes, assim como novas técnicas de produção e relações de trabalho, resultado do que Santos (1997) denomina de meio técnico-científico-informacional.

Acompanhando o processo globalizador a educação tem passado por modificações no que diz respeito às novas demandas sociais a serem atendidas e a própria visão de escola, o que por sua vez, impõe a necessidade de um repensar permanente do processo formativo, ganhando destaque nesse sentido a grande expansão dos cursos de formação de professores na modalidade da Educação a Distância (EAD).

Para Preti (1998; 2001) a grande expansão mundial que ocorreu com esta modalidade de ensino está ligada à reestruturação produtiva característica da nova ordem global que impôs novas demandas de qualificação aos trabalhadores. De início no Brasil, a implementação da EAD ocorre por uma necessidade de modificar as negativas estatísticas educacionais do país, cumprindo desta forma os dispositivos legais.

Se no setor educacional a globalização impôs novos ritmos e dinâmicas, também não foi diferente no que se refere ao setor ambiental. Na década de 1950 e 1960 alguns grupos sociais já alertavam e questionavam os valores da sociedade capitalista e na década de 1970, o mundo tem conhecimento do relatório do Clube de Roma sobre os alarmantes índices de degradação ambiental verificados em todo o planeta.

A partir de então a Educação Ambiental (EA) tem assumido uma importância fundamental na construção da sociedade atual, assim como na formação dos cidadãos críticos e reflexivos, uma vez que representa a possibilidade da construção de outra racionalidade ambiental que incuta desde a infância a necessidade de conservar os recursos naturais existentes, promovendo a justiça ambiental e garantindo a sustentabilidade. Bem como de valorizar os aspectos culturais de cada sociedade, a cooperação e o amor fraterno entre os indivíduos, para que atuando de forma coletiva alcancem os objetivos desejados.

A construção dessa racionalidade ambiental (LEFF, 2009) pode ser alcançada a partir do estabelecimento do ensino da Educação Ambiental que assume um caráter de relevância social, sendo entendida como um tema que deve perpassar todas as áreas do conhecimento, numa perspectiva inter/transdisciplinar, tal como é apontada pelos Parâmetros Curriculares Nacionais.

Na Ciência Geográfica, que a partir do espaço - entendendo-se este como habitado, vivido e transformado - busca-se compreender as relações estabelecidas entre Sociedade/Natureza, a presença da Educação Ambiental é Revbea, São Paulo, V. 12, № 2: 199-208, 2017. 
ainda mais forte, visto que é no meio dessas duas unidades complementares/discordantes que ela se encontra, formando a tríade Sociedade/Educação Ambiental/Natureza. Ou seja, é a partir das relações entre Sociedade/Natureza que emergem os problemas socioambientais que são o foco da Educação Ambiental, por isso a estreita relação entre essa dimensão educacional e a Ciência Geográfica.

A incorporação da Educação Ambiental nos cursos de formação de professores de geografia seja na forma de uma disciplina específica ou de atividades correlatas, representa a construção de um embasamento teóricometodológico fundamental para que os futuros professores possam sensibilizar seus alunos da educação básica para a construção de outra realidade socioambiental.

No entanto como nos alerta Coutinho (2009) mesmo a legislação orientando os profissionais da educação para a inserção da Educação Ambiental na educação formal, o que verificamos é um descompasso entre o que recomenda a Política Nacional de Educação Ambiental (PNEA), lei 9.795/99 e a formação de professores.

De acordo com o artigo $2^{\circ}$ da referida legislação:

Art. 2․ A Educação Ambiental é um componente essencial e permanente da educação nacional, devendo estar presente, de forma articulada, em todos os níveis e modalidades do processo educativo, em caráter formal e não-formal (BRASIL, 1999, p. 01).

Acerca deste fato, Tristão (2008) destaca que apesar da PNEA, muitos cursos de formação de professores ainda não incorporaram a Educação Ambiental em seus currículos e muitos outros que incorporaram não trabalham uma educação verdadeiramente ambiental, mas um conhecimento educacional sobre o assunto de forma parcelar, fragmentado, consonante com o paradigma da racionalidade técnica e instrumental.

Assim como Coutinho (2009) enfatizamos que a ocorrência da inserção da EA nas práticas pedagógicas dos egressos dos cursos de formação de professores perpassa pelo acesso à fundamentação teórico-metodológica para a formulação, gestão e monitoramento dos projetos de EA durante a formação acadêmica desses profissionais.

Caso contrário, quando implementada na educação básica a EA poderá ser caracterizada apenas como a apreensão de valores ecológicos e a construção de uma consciência ecológica, negligenciando outros aspectos que fazem parte do corpo conceitual que define a Educação Ambiental (LEFF, 2009).

Aspectos como o de justiça e desigualdade ambiental e da própria sustentabilidade, visto que buscá-la como assinala Layrargues (2009), pressupõe o enfrentamento não apenas da desigualdade ecológica, mas 
também social, política, cultural, entre outras; rememorando que o ambiental também abrange tais dimensões.

Sendo assim, este trabalho busca refletir sobre a incorporação da Educação Ambiental no curso de formação de professores de geografia da Universidade Federal de Sergipe (UFS) na modalidade EAD, e contribuir como fundamentação teórico-prática voltada para a Educação Ambiental, a partir do relato da aplicação de um minicurso para os alunos da EAD durante os encontros presenciais. Para tal, foram realizados levantamentos bibliográficos de autores como Tristão (2008), Coutinho (2009), Preti (1998; 2001), entre outros.

O levantamento sobre a EA no curso de geografia a distância da UFS foi realizado com professores e no sistema de gestão acadêmica da universidade. Complementando a pesquisa, foram analisados os relatos das atividades e dos participantes do minicurso: "A Educação Ambiental e o ensino de geografia: reflexão e ação no cotidiano escolar", ministrado no âmbito do $V$ Encontro Temático Disciplinar do Ensino de Geografia a Distância da Universidade Aberta do Brasil (UAB/UFS), realizado pelo Departamento de Geografia (DGE) e o Centro de Educação Superior a Distância (CESAD) da UFS, contando com a participação de alunos da graduação em Geografia/EAD dos diversos pólos que compõem a UAB no Estado de Sergipe.

\section{A Educação Ambiental no curso de Geografia EAD da Universidade Federal de Sergipe}

No curso de licenciatura em Geografia da Universidade Federal de Sergipe na modalidade à distância iniciado em 2007 através da UAB/CESAD/UFS, a Educação Ambiental é inserida como uma disciplina optativa de carga horária total de 60 horas. Cabe-nos ressaltar que mesmo a PNEA apontando em seu artigo 10, parágrafo 1ำ que a EA não deve constar como disciplina específica do currículo, esta realidade verificada no curso de licenciatura em Geografia apoia-se nas Diretrizes Curriculares Nacionais para EA publicada em 2012 buscando orientar os sistemas de ensino e suas instituições de Educação Básica e de Educação Superior para a abordagem da EA. Nesse sentido a presente resolução aponta no artigo 8ํㅜ, parágrafo único, que:

Art. 8․ Parágrafo único. Nos cursos, programas e projetos de graduação, pós-graduação e de extensão, e nas áreas e atividades voltadas para o aspecto metodológico da Educação Ambiental, é facultada a criação de componente curricular específico (BRASIL, 2012, p.03). Superior aponta que além da transversalidade; dessa inserção dar-se como conteúdo dos componentes curriculares; e da combinação destas duas formas: 
Art. 16. Parágrafo único. Outras formas de inserção podem ser admitidas na organização curricular da Educação Superior e na Educação Profissional Técnica de Nível Médio, considerando a natureza dos cursos (BRASIL, 2012, p.05).

Nesse sentido a ementa do referido componente curricular no curso de geografia visa oferecer o embasamento teórico necessário para o despertar da consciência ambiental no licenciando, para que em sua futura prática pedagógica possa ser um agente transformador do espaço multifacetado e globalizado no qual vivemos na atualidade, encontrando amparo legal nas Diretrizes Curriculares Nacionais para a EA.

A referida ementa apresenta os seguintes princípios balizadores: Origens da discussão e marcos epistêmicos referentes à educação e meio ambiente no mundo. Estilos de desenvolvimento e a problemática socioambiental. Declarações e documentos oficiais sobre educação e meio ambiente nos organismos internacionais e no Brasil: Tbilisi, Rio 92, Thessaloniki, Carta da Terra, PNEA/ProNEA. Fundamentos e pressupostos da Educação Ambiental no mundo e no Brasil. Concepções teórico-metodológicas em Educação Ambiental no Brasil. Ética ambiental. Sociedade civil e governo no sistema nacional de Educação Ambiental: desenvolvimento de projetos de pesquisa/ensino voltados à reflexão-ação-resolução dos problemas ambientais.

Além da referida disciplina e das disciplinas a distância do curso, os encontros presenciais tem demonstrado sua importância no diálogo e troca de experiências entre os alunos da EAD de Geografia da UFS. Semestralmente são promovidos encontros que possibilitam a referida troca de saberes, bem como são ofertados minicursos que buscam promover a ampliação prática dos conteúdos teóricos vistos durante o curso das disciplinas.

Dentre estes, o minicurso "A Educação Ambiental e o Ensino de Geografia: reflexão e ação no cotidiano escolar" realizado no final do semestre 2014, no âmbito do V Encontro Temático Disciplinar do Ensino de Geografia a Distância da Universidade Aberta do Brasil (UAB/UFS) possuiu uma duração de quatro horas e buscou analisar a teoria e a prática da Educação Ambiental no cotidiano escolar da disciplina Geografia através da caracterização da Educação Ambiental e da proposição de atividades pedagógicas para o seu desenvolvimento no contexto escolar.

O minicurso constituiu-se em um espaço de diálogo e troca de experiências, sendo realizado a partir de um encontro com alunos da licenciatura em geografia EAD da UFS, dos diversos pólos que compõem a UAB no Estado de Sergipe. Nele apresentamos aspectos conceituais que são importantes ao se tratar da EA, assim como atividades possíveis de execução na sala de aula, aprimorando o fazer pedagógico ambiental e construindo a possibilidade de outro cotidiano escolar. O que reforça a não formação de visões deturpadas no que se refere à Educação Ambiental e contribui para uma formação plena e totalizante aos graduandos em geografia e para uma futura 
prática docente autêntica e efetiva que culmine com o alcance dos objetivos primordiais da Educação Ambiental.

Algumas questões que nortearam a construção do referido minicurso foram: O que é Educação Ambiental? Quais as características da Educação Ambiental? Quais conteúdos podem ser trabalhados na Educação Ambiental? Quais atividades promovem a Educação Ambiental? O que diz a legislação sobre Educação Ambiental? Qual a relação entre Educação Ambiental e a geografia?

O desenvolvimento do minicurso realizou-se em dois momentos específicos: o primeiro de cunho teórico foi caracterizado pela exposição de aspectos fundamentais quando tratamos da temática da Educação Ambiental. De início os 30 participantes fizeram uma breve apresentação expondo seu nome e o pólo onde o curso era realizado, o que nos permitiu identificar uma grande heterogeneidade na turma, que possuía representantes de todo o Estado de Sergipe. Diante disso, aplicamos um questionário a fim de entender qual a percepção inicial acerca da EA sendo socializadas as respostas naquele instante e ficando facultada a devolução do mesmo ao ministrante.

Para abrirmos a explanação teórica apresentamos um vídeo e um conjunto de imagens que possuem estrita relação com a temática e a partir destes recursos solicitamos a conceituação da EA. Partimos para uma perspectiva histórica, apresentando alguns eventos internacionais de suma relevância na história da EA como a Conferência de Estocolmo, Tbilisi, Rio 92 e Rio+20 e em seguida destacamos algumas características que devem estar presentes no processo de ensino-aprendizagem da EA como: a necessidade de trabalhar a vivência do educando, o que coincide com uma das características do ensino da geografia; a necessidade de planejar e avaliar as atividades de EA; a busca pela sensibilização e conservação no lugar da conscientização e da preservação; a compreensão de que o meio ambiente não se refere apenas aos aspectos naturais, mas também sociais, políticos, econômicos, entre outros, como já ressaltam diversos autores do campo ambiental; e a necessidade do trabalho com a EA desenvolver-se numa perspectiva local/global visando a sustentabilidade e a justiça ambiental.

No que diz respeito à legislação realizamos uma breve interpretação da PNEA, além do que está prescrito no Sistema Nacional de Meio Ambiente (SISNAMA) e na legislação do Estado de Sergipe sobre a referida temática e, por fim, apresentamos os aspectos basilares para a construção de um projeto de ensino na EA.

Cabe-nos ressaltar que durante este primeiro momento, algumas dinâmicas como: um pé de consumo, pêndulo humano, cálculos da pegada ecológica, recomendadas por Dias (2010) e que facilmente podem ser inseridas nos conteúdos da geografia escolar foram realizadas como forma de manter o ambiente favorável à aprendizagem e para mostrar a aplicabilidade das mesmas nas salas de aula desses futuros docentes de geografia e sua relação com a EA. 
O segundo momento do minicurso foi marcado pela prática na confecção de atividades pedagógicas para sala de aula ${ }^{3}$. A turma foi dividida em quatro grupos, ficando cada um responsável pela elaboração de uma atividade. $O$ primeiro grupo trabalhou com a construção de um jogo da memória, contendo perguntas e respostas das imagens fornecidas e tendo como tema central "Problemas Ambientais Globais" sendo utilizado em sua confecção materiais como isopor, cola e palitos (Figura 1). O intuito foi fazer com que o grupo elaborasse perguntas para serem respondidas através das imagens presentes no jogo, que representavam diversos problemas ambientais do mundo globalizado, como aquecimento global, poluição das águas e do ar, efeito estufa, entre outros que estão diretamente relacionados com os conteúdos que seriam ministrados em suas práticas docentes na educação básica.

Para desenvolvimento do jogo o aluno teria que escolher um número correspondente à quantidade de questões formuladas pelo professor. Diante disso, o docente realizaria a pergunta e o aluno escolheria outro número, presente no painel, o qual continha uma imagem que poderia corresponder à resposta da pergunta feita pelo professor. Caso a imagem não respondesse à pergunta, deveria ser ocultada, cabendo ao aluno memorizar onde ela se encontrava para que quando a pergunta correspondente surgisse, o mesmo pudesse voltar a escolhê-la.

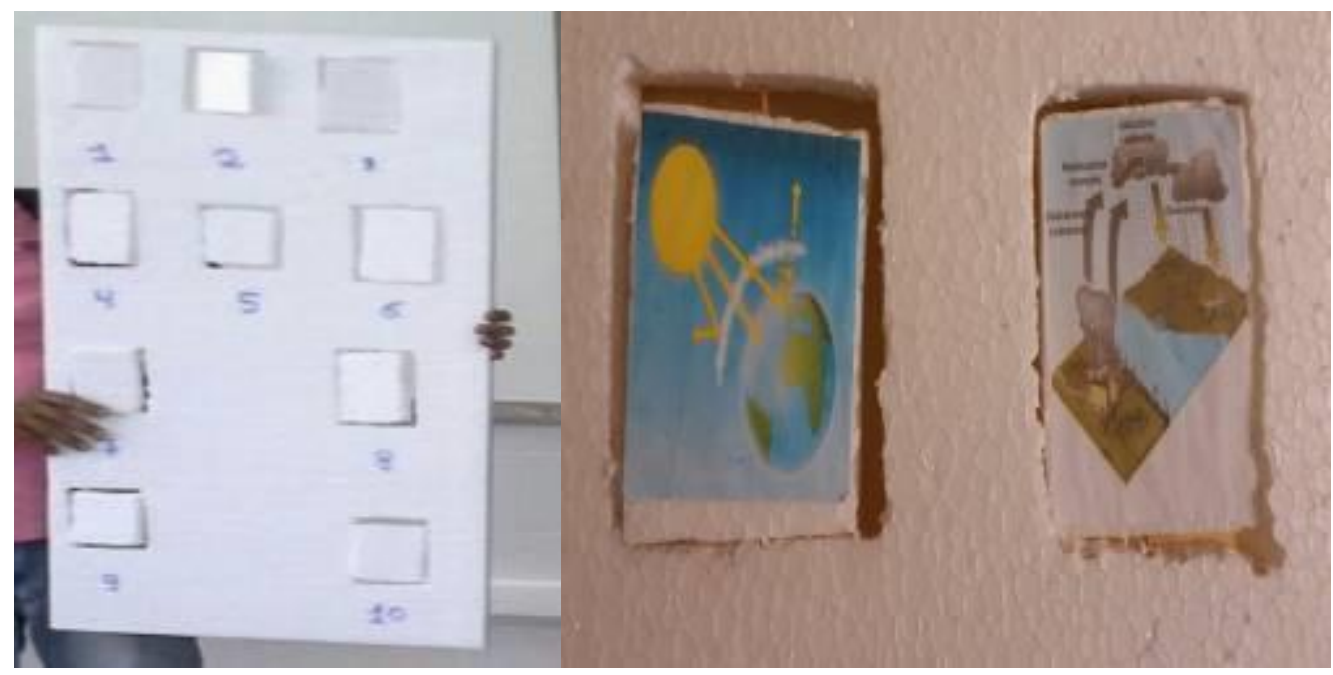

Figura 1: Jogo da memória. Fonte: Silva (2015).

O segundo grupo ficou responsável pela construção de uma trilha cujo tema central foi "Meio ambiente em Sergipe: do litoral ao sertão". Para tal foram utilizadas imagens que refletem características ambientais, sociais e econômicas do litoral, agreste e sertão sergipano - como os perímetros irrigados do alto sertão e o avanço do mar sobre a orla marítima no litoral sul além de materiais como isopor, cartolina, folhas de ofício, palitos, tesoura, cola,

\footnotetext{
${ }^{3}$ Buscando preservar a identidade e imagem dos participantes do respectivo minicurso optou-se por apresentar apenas os resultados das atividades pedagógicas confeccionadas.
}

Revbea, São Paulo, V. 12, № 2: 199-208, 2017.

revista brasileira 
pincel, entre outros. A partir dessas imagens, os participantes formaram pequenas legendas que traziam informações sobre a cena e direcionavam o usuário no jogo, possibilitando avançar algumas casas, ficar sem jogar ou retornar ao início do jogo (Figura 2).

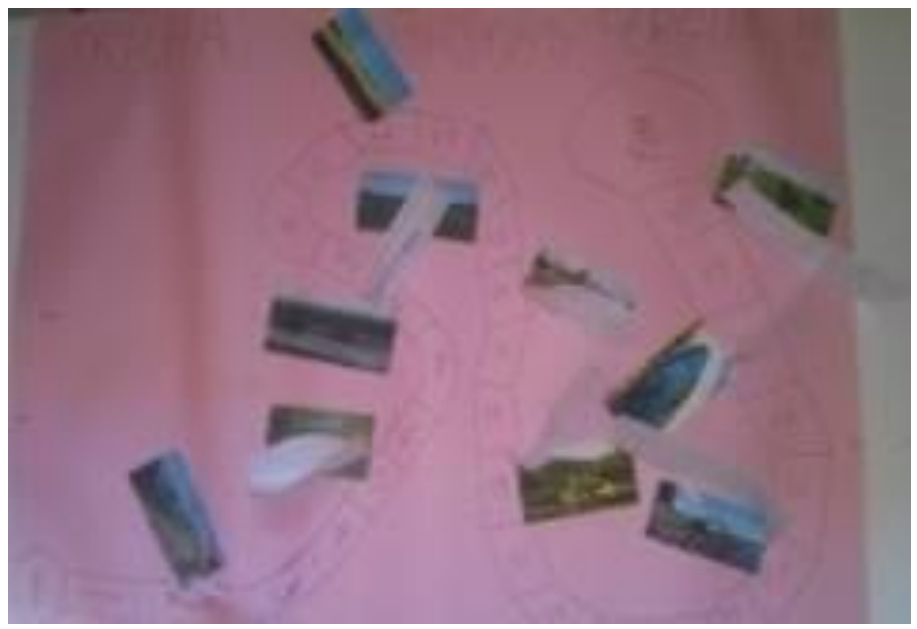

Figura 2: Trilha meio ambiente em Sergipe. Fonte: Silva (2015).

O terceiro grupo confeccionou um quebra-cabeça em material emborrachado, a partir de uma imagem característica do agronegócio. Para tal a imagem utilizada foi cortada de forma que pudessem montá-la novamente (Figura 3).

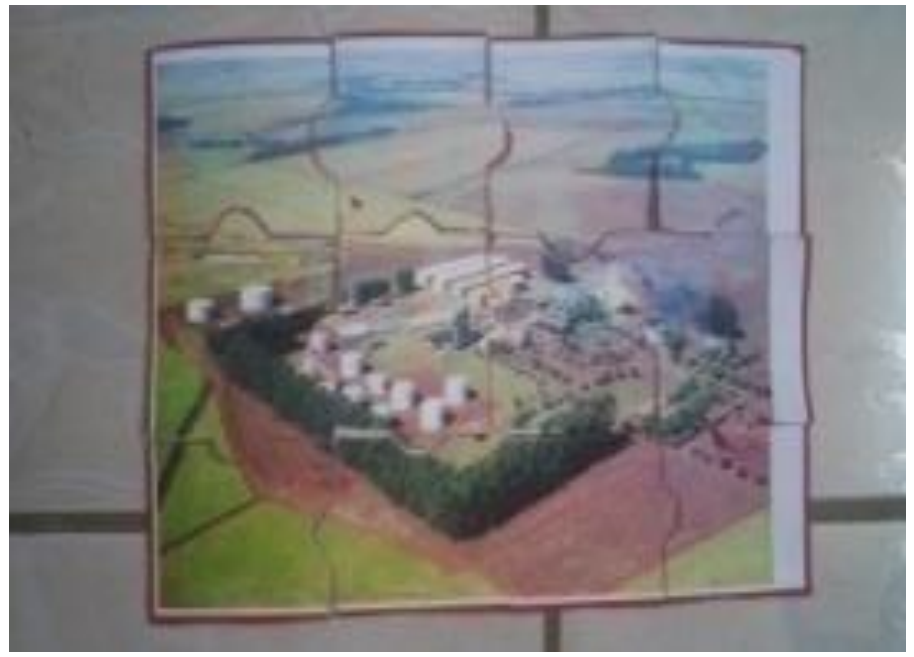

Figura 3: Quebra-cabeça. Fonte: Silva (2015).

Por sua vez, o quarto grupo realizou uma paródia envolvendo o tema poluição e tomando como base a música "Xote Ecológico" do consagrado cantor nordestino Luiz Gonzaga.

Com a construção das atividades cada grupo apresentou seus resultados enfocando como e em quais conteúdos poderiam utilizar a referida atividade na aula de geografia da educação básica. Sobressaindo-se que estas poderiam ser utilizadas como uma forma de revisão de conteúdos para a Revbea, São Paulo, V. 12, № 2: 199-208, 2017. 
avaliação ou até mesmo como parte desta, o que contribui para uma quebra na ideia de avaliação tradicional, uma vez que tais atividades criam a possibilidade de uma avaliação diagnóstica em vez de classificatória, como defende Luckesi (1999).

Cabe ressaltar o caráter lúdico das atividades propostas por entendermos que para a ocorrência da sensibilização, característica da Educação Ambiental, é preciso mobilizar as emoções e nesse sentido o lúdico contribui sobremaneira. Uma vez que chama a atenção para o desenvolvimento das atividades de forma prazerosa e criativa estimulando o raciocínio. Permitindo também o protagonismo do aluno no processo de ensino-aprendizagem, cabendo ao professor apenas o papel de mediador do conhecimento.

Tais atividades são importantes para a Educação Ambiental uma vez que buscam vincular a realidade local do aluno a uma global e vice-versa, além de desenvolverem-se na perspectiva de uma ação coletiva expressa pelo trabalho em grupo, sendo este um aspecto relevante do trabalho com a Educação Ambiental como aponta Guimarães (1995). Além disso, incentiva uma tomada de decisão visto que para isso é necessário conhecer causas e consequências dos problemas ambientais, sendo esta abordagem realizada através das atividades propostas.

Por fim as atividades contribuem para o processo formativo, pois coloca - aluno da graduação em contato com tais práticas que podem ser reproduzidas por eles quando estiverem na sala de aula da educação básica, dinamizando a aula de geografia.

\section{Considerações Finais}

A realidade socioambiental com a qual nos deparamos força-nos a fazer da Educação Ambiental uma realidade concreta e não um modismo espalhado ao vento. Dessa forma, incorporá-la na formação dos futuros professores é comprometer-se com a construção desta concretude. Diante disso, é louvável percebermos a inserção da EA no curso de formação de professores de geografia em EAD da UFS, uma vez que tal fato representa um comprometimento ideológico com a formação da sociedade atual, além de servir como exemplo para os demais cursos que ainda não perceberam a importância da inserção desta dimensão educacional em seus currículos.

Cabe-nos destacar a importância dos encontros presenciais desenvolvidos pelo curso, pois além da proposição das atividades práticas para serem desenvolvidas quando estes professores estiverem em sala de aula, há também a troca de experiências e o fortalecimento de vínculos interpessoais como ressalta Kenski (2003). Estes garantem que a formação mesmo no curso a distância, não ocorra de forma distante, mas que esteja o mais próximo possível do lócus do conhecimento científico, representado pela universidade e as relações que perpassam tal espaço. 
Além disso, tais encontros permitem a construção de trabalhos como este, que contribuem para a consolidação da Educação Ambiental na educação formal a partir da socialização de atividades possíveis de aplicação nos conteúdos cotidianos da geografia escolar que muitas vezes não são socializadas para a comunidade acadêmica.

Enfim, é necessário que a formação de professores em EAD não esqueça do seu compromisso social, possibilitando uma formação plena e totalizante a todos que passem por essa modalidade de ensino, o que se traduz entre outros aspectos, pela incorporação da dimensão ambiental em seus currículos formativos.

\section{Referências}

BRASIL. RESOLUÇÃO № 2, DE 15 DE JUNHO DE 2012, que estabelece as Diretrizes Curriculares Nacionais para a Educação Ambiental. DOU no 116, Seção 1, págs. 70-71 de 18/06/2012.

BRASIL. Lei № 9.795, de 27 de Abril de 1999. Institui a Política Nacional de Educação Ambiental. Brasília: DF, Diário Oficial da União, 28 de abril 1999.

COUTINHO, S. A Educação Ambiental na formação de professores. In: SEABRA, G. Educação Ambiental. João Pessoa: Ed.UFPB, 2009, p.39-51.

DIAS, G.F. Dinâmicas e Instrumentalização para Educação Ambiental. 1 ed. São Paulo: Gaia, 2010. .

GUIMARÃES, M. A dimensão ambiental na educação. Campinas, SP: Papirus, 1995.

KENSKI, V.M. Tecnologias e ensino presencial e a distância. Campinas, SP: Papirus, 2003. - (Série Prática Pedagógica).

LAYRARGUES, P.P. Educação Ambiental com compromisso social: o desafio da superação das desigualdades. In: LOUREIRO, C.F.B.; LAYRARGUES, P.P.; CASTRO, R.S. (Orgs.). Repensar a Educação Ambiental: um olhar crítico. São Paulo: Cortez, 2009, p.11-31.

LEFF, E. Saber Ambiental: sustentabilidade, racionalidade, complexidade, poder. Tradução Lúcia Mathild Endlich Orth. Petrópolis, RJ: Vozes, 2009.

LUCKESI, C.C. Avaliação da aprendizagem escolar: estudos e proposições. 9. ed. São Paulo: Cortez, 1999.

PRETI, O. A formação do professor na modalidade a distância: (des)construindo metanarrativas e metáforas. Revista Brasileira de Estudos Pedagógicos. Brasília, v.82, n.200/201/202, p.26-39, jan./dez. 2001.

PRETI, O. Educação a distância e globalização: desafios e tendências. Revista Brasileira de Estudos Pedagógicos. Brasília, v.79, n.191, p.19-30, 1998.

SANTOS, M. Técnica, espaço, tempo: globalização e meio técnico-científicoinformacional. 3 ed. São Paulo: Hucifec, 1997.

TRISTÃO, M. A Educação Ambiental na formação de professores: redes de saberes. $2^{\text {a }}$ ed. São Paulo: Annablume, 2008. 